\title{
The Role of World Oil Price in The Movements of the Asian Stock Market
}

1,2 Le Thi Minh Huong

\author{
${ }^{1}$ School of Economics, Huazhong University of Science and Technology, Hubei, China \\ ${ }^{2}$ Faculty of Economics, Danang Architecture University, Danang, Vietnam
}

\begin{abstract}
This article provides insight into the cross-border role of oil on Asia's largest stock markets. The research was conducted using VAR, GARCH_BEKK $(1,1)$, and related tests such as stationarity, correlation, and causality tests. The results obtained suggest that the time series of data ensure conditions for analysis. Asian stock prices are inversely related to oil prices in a correlation. At the same time, in considered stock markets, the Korean stock market and world oil prices appear to have a causal relationship with each other. Moreover, the tests of profitability and volatility in oil prices also indicate a link with the Korean stock market during the research period.
\end{abstract}

Keywords: World oil price, Return, Volatility, the Asian stock market, GARCH model

\section{Introduction}

The stock market is one of the channels for measuring economic development of a country and is also considered to be very useful when stock prices are adjusted very quickly when new information about the market is published. Securities market also promotes its essential role in the field of domestic and foreign capital mobilization. Psychological factors of investors, as well as the regulation of government policies and fluctuations of macroeconomic variables, are always included when positive or negative changes to the stock price index occur.

Petroleum is one of the vital inputs of almost every industry in the economy. The fluctuation of oil prices has a direct impact on the global economy, and the energy security of numerous countries. The stock market will be severely affected by the big shocks of oil price volatility due to uncertainty and fear of risks in investors' financial markets. All of those reasons led to panic and caused a drop in the stock price index. On the other hand, when an oil price shock occurs, it will indirectly affect the profitability of the stock market by a decline in industrial production.

In recent years, the role of world oil on stock market volatility has attracted a lot of attention from researchers around the world. People often consider crude oil to be the backbone of the industry, and price fluctuations will have a multidimensional impact on oil producers and consumers. When the price of oil increases, producers will benefit and vice versa for businesses that consume oil or use oil-derived materials. Therefore, increasing of oil price has led to changes in charges between different stock groups in the market. This article attempts to explore the role of world oil prices on Asian countries' stock markets to assess the spillover effects from these markets.

\section{Literature Review}

Many scholars are quite interested in analyzing empirical research on the role of world oil prices on the stock market; such is the study of Hamilton (1983) regarding the oil price shock on the US stock market. The theoretical economic foundation at which he initiated the research is quite 
famous, focusing on the statistical correlation between two analytical variables. He noted that, during eight economic recessions, there were seven times the world witnessed a significant increase in crude oil prices. He found no evidence that inventories, capacity utilisation, a series of leading indicators of the Bureau of Economic Analysis, interest rates, and the stock market could predict the oil price shock in 1948-1972. L. Kling (1985) followed research on the US stock market from 1973 to 1982 . The results revealed that the US stock market has changed based on the oil price shock with the delayed impact on the securities of the aviation and automotive industry. As a result, oil prices affect not only the relevant macroeconomic variables but also the financial markets.

Jones \& Kaul (1996) collected observational data to study the role of oil in the post-war period for four countries, including the United States (from 1947-1991), Canada (1960-1991), Japan (1970-1991), and England (1962-1991). The study revealed world oil price is the reason for the fluctuations in the production and profitability of stocks in the US and Canada markets. The author also clarifies the opposite impact of observed variables in the research period.

Also, with the scope of research on the US stock market, Sadorsky (1999) studied the oil prices in the period from 1947 to 1996 . The author has implemented the vector automatic regression method to find out that both changes in oil prices and their volatility affected the US stock return. In more detail, positive shocks in oil prices reduced US stock return. On the contrary, the results also indicate that compared to the influence of interest rates after 1986, error variance in the model predicting future stock return affected the oil price shocks. Moreover, the analysis shows the asymmetry between the oil price volatility and the fluctuation of stock return in the economy. Also, using the above method of vector autoregressive analysis, there have been many studies that have expanded the scope in many different markets, such as Malaysia (Yahya et al., 2013), and India and Pakistan (Fatima \& Bashir, 2014). The conclusions from the above studies have made similar implications. A study carried out in India during 2010-2017 found that energy index affected the latency of future crude oil prices in India. The impulse response function shows that crude oil price has adverse effects with a standard deviation shock of stock indices Sharma et al., (2018).

When considering the causality of variables in stock and oil markets, many studies still argue about the non-correlation between the two variables. However, when considering dynamic nonlinear relations between them, Ciner (2001) gave a different perspective on this relationship. Accordingly, US stock return on the S\&P 500 stock index and oil return have a nonlinear causal relationship. This reciprocal relationship has intensified since the 1990s. Along with applying the above method on Canadian, German, British, and American securities, Jammazi, Lahiani, \& Nguyen (2015) have added that an oil shock in a stable price environment could have a more significant effect on stock return than in a volatile price environment.

Concerning the different risks of oil price fluctuations on the emerging stock markets from 1992 to 2005 , Basher \& Sadorsky (2006) combined the method of conditional and unconditional factor risk analysis on many different types of risks to analyse the critical role of oil price risk to stock market risk. The risk of oil price return is one of the factors that individual investors and institutional investors use to value stocks in the emerging stock markets.

In recent years, the topic of the spillover phenomenon of economic factors in the financial market attracted the attention of many scholars. In particular, the spread of return of oil prices on the stock market in the US, Europe, and other countries emerged. Researches include the study of Park \& Ratti (2008); Mohanty, Nandha, \& Bota (2010); Arouri, Lahiani, \& Nguyen, (2011), El Hedi Arouri, Jouini, \& Nguyen (2011); Fayyad \& Daly (2011); Cunado \& Perez de Gracia (2014). In examining Vietnam's stock market, Nguyen \& Bhatti (2012) used both parametric and nonparametric methods and concluded on the left-tail dependence between world oil prices and 
stock price indices. However, the author of the study described a tail-dependent relationship was not found in the Chinese stock market.

In the Indian market, with a daily research data series from 2000 to 2001, Chittedi (2012) used the ARDL model. After investigating the linkages from the variability of oil prices and stocks, the authors did not find causality stock prices and oil prices. Gokmenoglu \& Fazlollahi (2015) used this model to determine the role of oil prices in the US stock market. Accurately, the long-term equilibrium of the S\&P500 stock price index will converge to balance at a rate of $1.2 \%$ compared to the fluctuation of world oil prices.

Meanwhile, in Turkey, the speed of reaching the long-term equilibrium of stock prices reached $0.39 \%$ of oil and gold prices rate. A positive relationship was found between the price of crude oil and the stock market from this country (Tursoy \& Faisal, 2017). This phenomenon is different from the Vietnamese market where the one-directional linkage between oil and securities exists only in the short term, and the inverse relationship takes place in the long run, (Khai, Sang, Thi, \& Nguyet, 2017).

While many previous studies have pointed out the critical role of oil prices on the stock market, there are also studies showing the opposite results. One such study is an article by Siddiqui \& Gaur (2017) in India that applied a multivariate GARCH model to a 3-year data sample from 2014 to 2016. The authors presented that There is no unification or causal relationship between variables. The spread of exchange rate fluctuations, stock indexes, and crude oil was negligible. The association also has a different level of effects depending on the observation period. For example, before the economic crisis, the weak linkage took place but increased significantly after the economic recessions (Ferreira, Johson, Leão, Fernandes, \& Pereira, 2018). Extending the method from the multivariate GARCH model, Zankawah \& Stewart (2019) used the GARCH BEKK and TBEKK model in the Ghana market from 1991 to 2005. The author simulated the role of how oil prices go up in the stock market. The study suggested that different conclusions can be drawn depending on whether the oil price is endogenous or exogenous, so the results will be different.

\section{Methodology and Data}

From the models of previous studies, the paper proposes an analytical model with the following general equation:

Index $_{i}=f($ Oil $)$

In which: Index $i$ is the price index of Asian stock markets, respectively, in countries: China, Japan, India, Hong Kong, and South Korea. These stock markets have the largest trading volume representing Asian stock markets for many consecutive years over the last decade. All variables included in this research model will be converted to a natural Logarithm to reduce the high dispersion in the observed variables. As well as using data in the form of logarithms to facilitate the identification and analysis of data when the statistical sample has some unusual observations of the original data. The following formula will determine the profitability of the data series in stock prices:

Index_R $R_{i}=\log \left(P_{i} / P_{i-1}\right)$

In which, $\mathrm{Pi}$ is the index of closing stock prices of the securities market $\mathrm{i}$ time $\mathrm{t}$ converted to logarithms; $\mathrm{Pi}-1$ is the stock market closing price at the time $\mathrm{t}-1$ converted in logarithms. The same formula applies when calculating the oil price return. The Bivariate VAR model is applied when considering the role of world oil prices and the stock market return of Asian countries. The specific equation expressed as follows: 


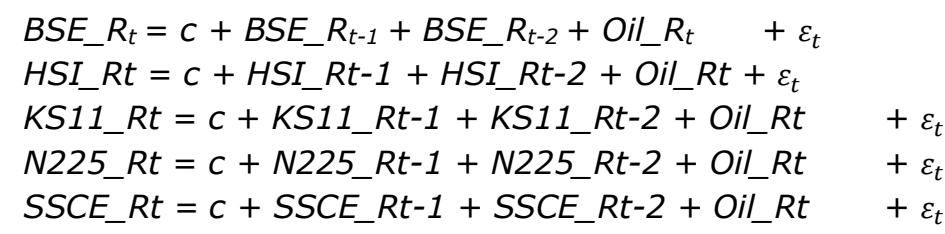

It is necessary to check the stationarity of the data series, and the author conducts an Augmented Dickey-Fuller (ADF) test. Also, the author reassessed to ensure the importance of analysing the data series by the Philips-Perron (PP) test. The heterogeneous variance test of profit margin series residuals is performed by LM (LagrangeMultiplier Test) for ARCH. Heterogeneous variance tests are conducted on residuals before applying the GARCH method because the fluctuations in the rate of return of assets are correlated. (Engle, 1982) conducted a study of time series data through describing the value of different time variables, a phenomenon called conditional error variance and autocorrelation phenomenon (ARCH). We perform the $\mathrm{ARCH}$ model as follows:

$\delta_{t^{2}}=\omega+a(L) \eta t^{2}$

In which, $a(L)$ is a polynomial in the lag variable. For the variance to have a positive condition, $\omega$ and $a(L)$ must be non-negative. However, many scholars argued that the ARCH ( $p)$ is only suitable for financial models with sufficiently large latency, and this ensures extensions for the ARCH model. The GARCH model discovered by (Bollerslev, 1986) based on serial fluctuations. The following formula represents the GARCH model:

$Y_{t}=\beta_{1}+\beta_{2} X_{t}+u_{t}$

$\mathrm{u}_{\mathrm{t}} \sim \mathrm{N}\left(0, \mathrm{~h}_{\mathrm{t}}\right)$

$\mathrm{h}_{\mathrm{t}}=\mathrm{Y}_{0}++\sum_{i=1}^{p} \delta_{i} h_{t-i}+\sum_{j=1}^{q} \gamma_{j} u_{t-j}^{2}$

Where (9) is the mean equation, (10) is the equation of variance, this equation indicates that the variance ht now depends on the historical value of shocks, represented by the late variables of the square noise class, and the past values of ht itself, represented by the variables ht-i. If $p$ $=0$, meaning the order of AR equals 0 , then the $\operatorname{GARCH}(0, q)$ model is simply an ARCH (q) model. When $\mathrm{p}=1, \mathrm{q}=1, \operatorname{GARCH}(1,1)$ abbreviated as follows:

$h_{t}=\gamma_{0}+\delta_{1} h_{t-1}+\gamma_{1} u_{t-1}^{2}$

To ensure the conditional variance is non-negative, the coefficients $\delta 1, \gamma 1$ must be $\geq 0$.

$\delta 1$ measures possible fluctuations in the next period. If $\delta 1$ is high, it can indicate that the fluctuations changing the market are strong. If the coefficient is cao1 high, that indicates longterm volatility. Besides, if $\delta 1$ is high and $\gamma 1$ is low, the volatility is extreme. If the sum of $\delta 1$ and $\gamma 1$ equals 1 , a shock at time $t$ will last for a long time. If the sum of $\delta 1$ and $\gamma 1$ is less than 1 , it will result in frequent changes over the long term. If the sum of $\delta 1$ and $\gamma 1$ is 1 , shocks will temporarily change future values. The GARCH model based on the dependence on a series of fluctuations, making future observations based on past observations, so the GARCH model based on the variance that changes over time.

The GARCH model of Engle (1982) and Bollerslev (1986) became the theoretical basis for further extended research. Respectively, Engle \& Kroner (1995) conducted generalised parameterisation on the variance equation with minimising the parameters to be estimated but still ensuring the positive determination of the Ht matrix is called the BEKK model. The GARCHBEKK model $(1,1)$ is as follows:

$H_{t}=M^{T} M+A^{T} u_{t-1} u_{t-1}^{T} A+B^{T} H_{t-1} B$ 
Corresponding to each pair of variables are world oil prices and stock prices from Asian stock markets of interest; we can write the model in the form of a matrix as:

Where $H_{t}=\left[\begin{array}{ll}h_{11, t} & h_{12, t} \\ h_{21, t} & h_{22, t}\end{array}\right], M=\left[\begin{array}{cc}m_{11, t} & m_{12, t} \\ 0 & m_{22, t}\end{array}\right], A=\left[\begin{array}{ll}a_{11, t} & a_{12, t} \\ a_{21, t} & a_{22, t}\end{array}\right]$ and $B=\left[\begin{array}{ll}b_{11, t} & b_{12, t} \\ b_{21, t} & b_{22, t}\end{array}\right]$

\subsection{Research Data}

The model of daily time series data variables for ten years from 2010 - 2020 was taken from published official sources such as investing.com, yahoofinance.com to Collecting data of world oil prices, and stock indexes of Asian stock exchanges. The research model was developed, including the dependent variable, which is the stock price index of 5 representative markets of Asia, and the independent variable is World Oil Price. Data collected on world oil prices are equal to the daily average of WTI crude oil traded on the NYSE. We use daily data rates to capture more information about stock prices (Li \& E.Giles, 2015). Inheriting studies on (Ciner, 2011), the method used is a quantitative method, based on GARCH models (Bollerslev, 1986) to measure the degree of variability and Granger Kernel Test, (Granger \& Lin, 1995) to check for spillover effects. From the raw data on stock price indexes and oil prices, the study performed daily return calculations in the above markets before conducting the analysis. The reason for choosing this research phase is because this is a 10-year period from the world financial crisis. The study aims to assess the interdependence between stock markets in the recovery phase. Even though markets have grown, investors can still be cautious. Usually, in the volatile history of the world economy with a 10-year cycle, investors are quite sensitive to news and changes from the market. The variables respectively named according to specific regulations from the stock exchanges of the representative stock markets in Asia. Accurately, the following variables, BSE, HSI, KS11, N225, SSEC, and OIL, represent the price index from stock exchanges in India, Hong Kong, Korea, Japan, China, and oil prices

\section{Results and Discussion}

\subsection{Data Analysis of Observed Variables}

Over the years, the stock price indexes of most markets tended to increase steadily. The graph from Figure 1 has shown that the Indian stock exchange has grown quite vibrant, displaying fast growth, especially in the period from 2017 to 2020. Shanghai Stock Market had a definite change in the years 2015 and 2016. Chinese stock prices at this period soared and peaked. After that, the market goes down, and there is little price fluctuation. Although the stock indexes have increased in the remaining markets, including Hong Kong, South Korea, and Japan, the increase is not significant. Contrary to the uptrend of the stock market, world oil prices tend to go down and fall over the years. One of the explanations for this phenomenon is the increasing supply of oil prices around the world.
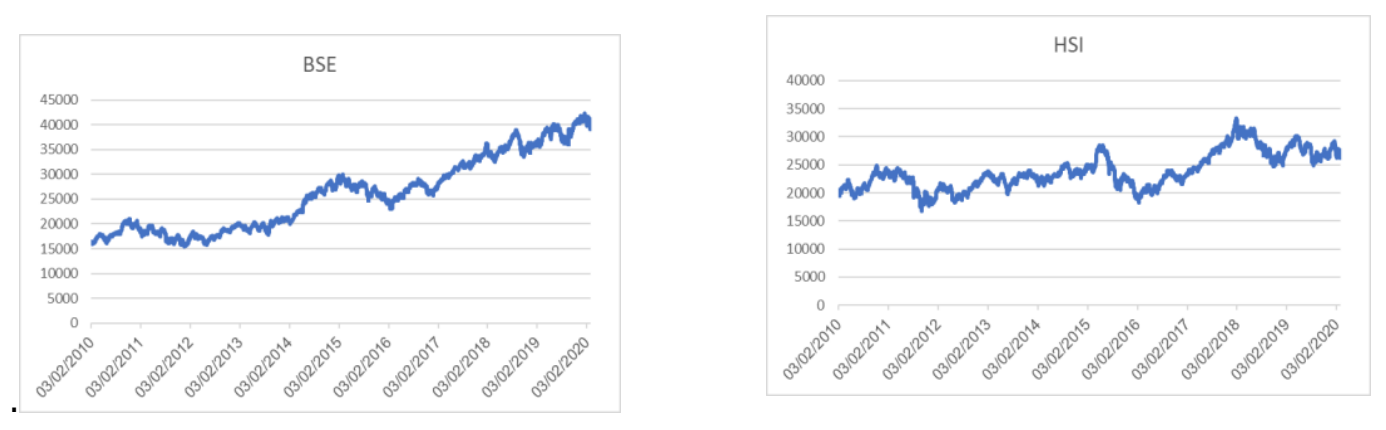

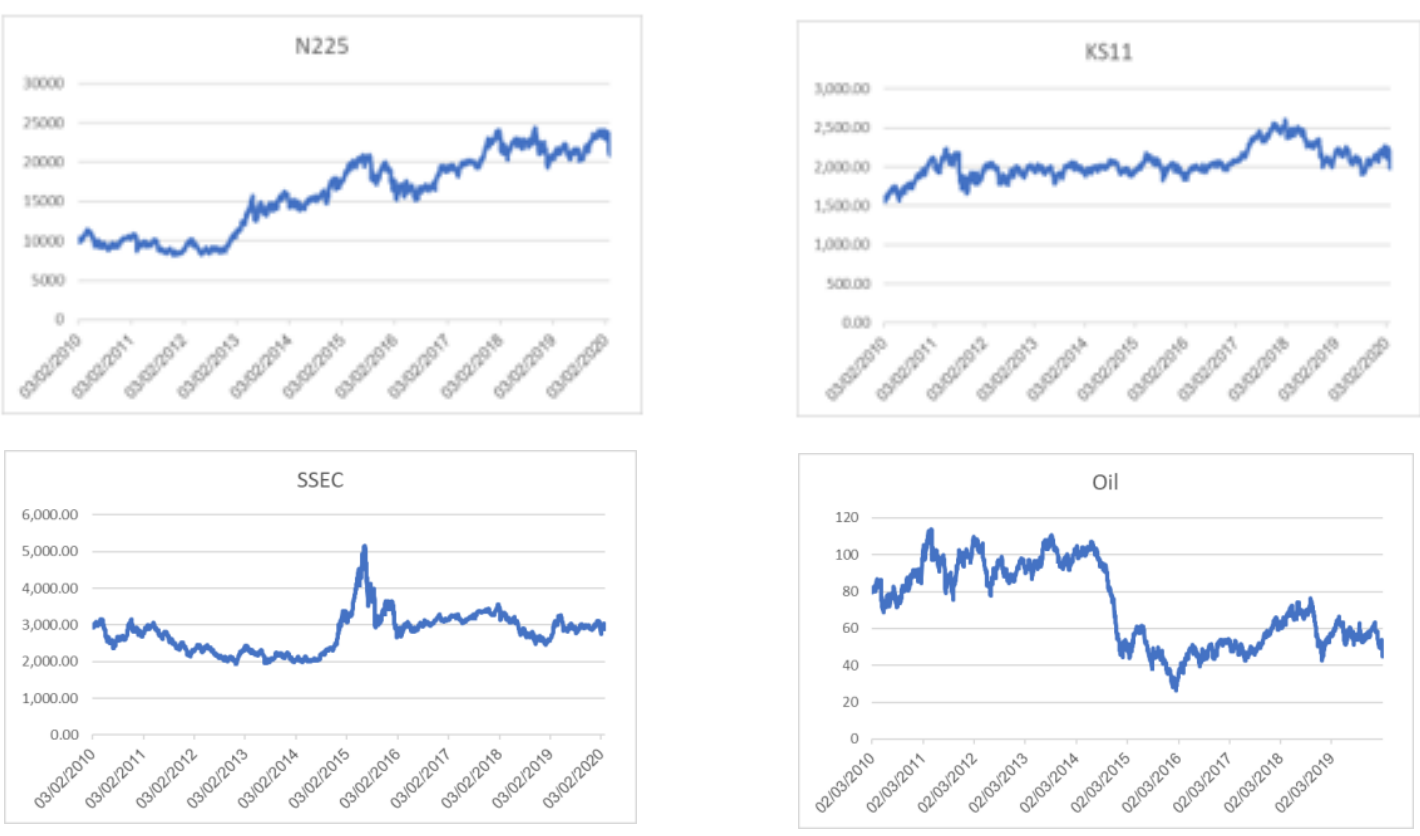

Figure 1: Stock market volatility in Asian markets

With the characteristics of different trading rules at the stock exchanges, as well as the holidays, the number of different securities trading days leads to a difference in observations in the sample of each specific variable. We collected the data in the period 2010 to 2020 of the variables from Table 1 revealed that the most significant number of observed samples was the oil price with 2519 trading days; the remaining variables had different numbers of observations around 2470 days. Values are positive for all stock markets, except for the Shanghai stock index and oil price. This result shows that in these two markets, a downward trend prevailed over an upward trend. A sharpness factor greater than 3 implies that the rate of return chain has a long and thick tail and does not follow the standard distribution law. The Jarque - Bera test is statistically significant at the $1 \%$ level, which means that we rejected the usual distribution hypothesis. Also, when looking at the standard deviations of the data series, it can be seen that the uncertainty in the value of oil and stock prices in Shanghai, Japan, Hong Kong, India, and South Korea tends to descend, respectively.

Table 1: Descriptive statistics of the Asian stock market return and oil price return

\begin{tabular}{|l|l|l|l|l|l|l|}
\hline & BSE_R & N225_R & SSEC_R & KS11_R & HSI_R & OIL_R \\
\hline Mean & 0.000356 & 0.000281 & $-1.72 E-05$ & $8.34 \mathrm{E}-05$ & 0.000100 & -0.000229 \\
\hline Median & 0.000466 & 0.000640 & 0.000504 & 0.000326 & 0.000433 & 0.000436 \\
\hline Maximum & 0.070082 & 0.056557 & 0.056036 & 0.049000 & 0.055324 & 0.136944 \\
\hline Minimum & -0.047821 & -0.075037 & -0.088729 & -0.064202 & -0.060561 & -0.107942 \\
\hline Std. Dev. & 0.009863 & 0.012153 & 0.013674 & 0.009376 & 0.011471 & 0.020510 \\
\hline Skewness & -0.004643 & -0.361119 & -0.979997 & -0.478994 & -0.250796 & 0.037770 \\
\hline Kurtosis & 5.472497 & 6.116777 & 9.335779 & 7.097271 & 4.973027 & 6.334700 \\
\hline Jarque-Bera & 629.6729 & 1051.315 & 4480.837 & 1832.506 & 427.2219 & 1167.759 \\
\hline P-value & $<1 \%$ & $<1 \%$ & $<1 \%$ & $<1 \%$ & $<1 \%$ & $<1 \%$ \\
\hline Number of Days & 2472 & 2465 & 2445 & 2484 & 2474 & 2519 \\
\hline
\end{tabular}

Source: Author calculations 
From the return chart in Figure 2, it is evident that the rate of return of securities and oil prices can be a series of pauses and may have an ARCH effect because of the fluctuations of $\mathrm{R}$ around the value of zẻo. Trends of strong or weak volatility of the amount of variance followed by the same pattern of variations in the most recent period (successive trends, and cluster fluctuations). The mean is constant, but the difference changes over time

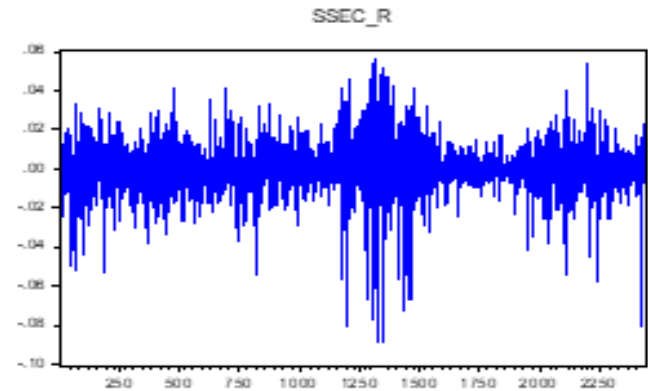

KS11_R
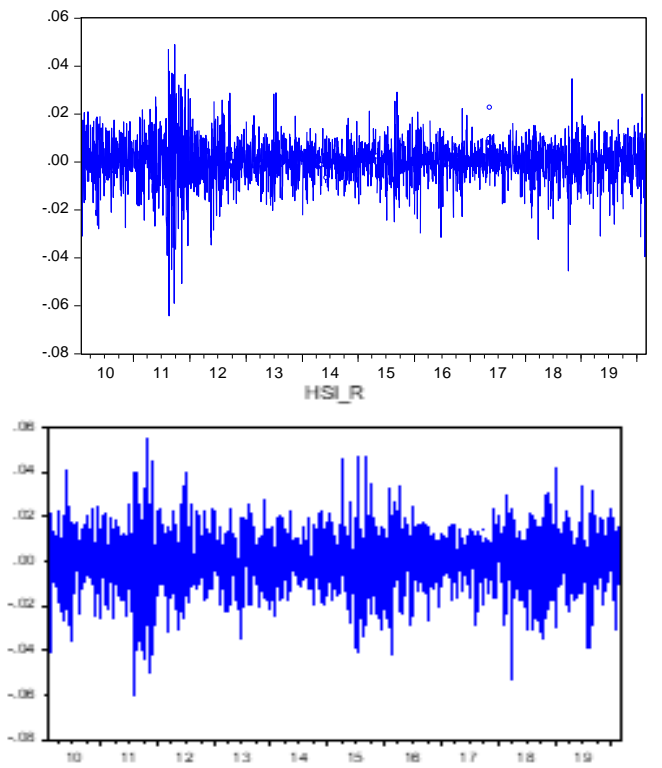
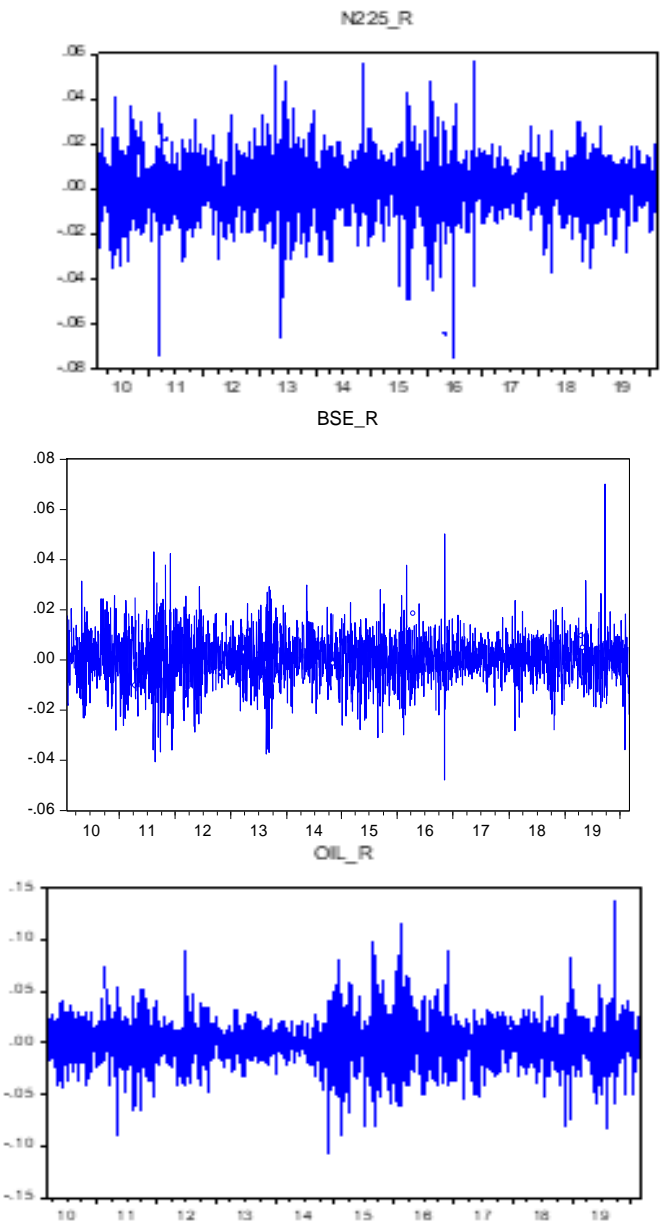

Figure 2: Daily return of stocks and oil prices

\subsection{Evaluation of Stationarity of Data Series}

Table 2 shows stationary test results using ADF and PP tests. The p-value of ADF and PP is less than 0.05 . Besides, the results of the ADF and PP tests rejected the hypothesis at $1 \%$ with critical value -3.43 , and this result can conclude the time series data involved. In this study, all variables have stationary at the first difference.

Table 2: Unit root test

\begin{tabular}{|l|l|l|l|l|}
\hline & \multicolumn{2}{|c|}{ Level } & \multicolumn{1}{c|}{$1^{\text {st }}$ difference } \\
\hline & ADF & PP & \multicolumn{1}{c|}{ ADF } & PP \\
\hline KS11 & $-2.952206^{* *}$ & $-2.968184 * *$ & $-48.44472^{*}$ & $-48.42146^{*}$ \\
\hline N225 & -1.018563 & -1.035743 & $-46.98264^{*}$ & $-46.91476^{*}$ \\
\hline SSEC & -2.272025 & -2.247902 & $-22.25963^{*}$ & $-46.45429^{*}$ \\
\hline BSE & -0.404589 & -0.335377 & $-50.04123^{*}$ & $-50.11425^{*}$ \\
\hline SSEC & -2.140938 & -2.182104 & $-47.75762^{*}$ & $-47.73396^{*}$ \\
\hline OIL & -1.278580 & -1.261790 & $-52.49544^{*}$ & $-52.45058^{*}$ \\
\hline
\end{tabular}

Source: author calculations $(*, * *$ mean probability less than $1 \%, 5 \%$, respectively) 


\subsection{The Pair Correlation of Observed Variables}

The result of the pair-correlation analysis of the observed variables presented in tables $3 \& 4$ shows that oil prices inversely correlated with all variables of the stock index on Asian markets. This outcome is visually depicted in the graphs presented above. When the Asian stock markets' price indexes tend to go up, and oil prices tend to go the opposite way, the price decreases gradually over the years. In particular, considering the absolute value of the numbers, we see that oil prices are strictly related to stock prices on the Indian market (BSE), Japan (N225), and the Shanghai market (SSCE). When looking at the relationship of Asian stock markets together, it is easy to see the close relationship of the stock markets of India, South Korea, Hong Kong, and Japan, along with the correlation value above $65 \%$. Shanghai stock index seems to have a weak relationship with the rest of the market

Table 3: The pair correlation test of 6 observed variables

\begin{tabular}{|l|l|l|l|l|l|l|}
\hline & BSE & HSI & KS11 & N225 & SSCE & OIL \\
\hline BSE & 1.000000 & & & & & \\
\hline HSI & $\mathbf{0 . 8 2 5 7 0 6}$ & 1.000000 & & & & \\
\hline KS11 & $\mathbf{0 . 6 7 6 8 0 6}$ & $\mathbf{0 . 8 2 0 3 2 0}$ & 1.000000 & & & \\
\hline N225 & $\mathbf{0 . 9 3 4 2 4 3}$ & $\mathbf{0 . 7 9 5 1 7 2}$ & $\mathbf{0 . 6 8 3 7 9 9}$ & 1.000000 & & \\
\hline SSCE & 0.471550 & 0.465974 & 0.361053 & 0.541893 & 1.000000 & \\
\hline OIL & $\mathbf{- 0 . 6 4 6 6 6 6}$ & -0.374496 & -0.350605 & $\mathbf{- 0 . 6 9 0 7 1 5}$ & $\mathbf{- 0 . 7 2 2 2 4 1}$ & 1.000000 \\
\hline
\end{tabular}

Source: author calculations

Meanwhile, the return on the self-correlation matrix of the observed data series has only a minimal relationship between the world oil market and the Asian stock market. This figure helps us to compare the differences in the relationship between actual prices and returnability of the observed chains. In general, self-correlated values are minimal, and even the most substantial amount is only approximately $2 \%$ in the relationship of oil price return to the return of Shanghai, Japan stock markets, and Hongkong.

Table 4: The pair correlation test of 6 return variables

\begin{tabular}{|l|l|l|l|l|l|l|}
\hline & BSE_R & HSI_R & KS11_R & N225_R & SSCE_R & OIL_R \\
\hline BSE_R & 1.000000 & & & & & \\
\hline HSI_R & 0.051303 & 1.000000 & & & & \\
\hline KS11_R & 0.023246 & 0.018188 & 1.000000 & & & \\
\hline N225_R & 0.010803 & 0.074247 & 0.049081 & 1.000000 & & \\
\hline SSCE_R & -0.003743 & 0.039337 & -0.005008 & -0.015644 & 1.000000 & \\
\hline OIL_R & 0.006550 & $\mathbf{0 . 0 2 1 7 3 5}$ & 0.006258 & $\mathbf{0 . 0 2 3 6 2 2}$ & $\mathbf{0 . 0 2 6 2 7 9}$ & 1.000000 \\
\hline
\end{tabular}

Source: author calculations

\subsection{The Impact of the World Oil Price Return on The Asian Stock Market Return Using the Bivariate VAR Model}

The equation of the VAR analysis model applied as analysed above, and after running the test, we collect the results in Table 5 as follows.

Table 5: The impact of the world oil price return on the Asian stock market return

\begin{tabular}{|c|c|c|c|c|c|}
\hline & BSE_R & HSI_R & KS11_R & N225_R & SSCE_R \\
\hline \multirow{3}{*}{ OIL_R(-1) } & -0.004670 & -0.011720 & -0.014784 & 0.007325 & 0.004942 \\
\cline { 2 - 6 } & $(0.00969)$ & $(0.01124)$ & $(0.00918)$ & $(0.01194)$ & $(0.01350)$ \\
\cline { 2 - 6 } & {$[-0.48196]$} & {$[-1.04250]$} & {$[-1.60965]$} & {$[0.61335]$} & {$[0.36617]$} \\
\hline \multirow{3}{*}{ OIL_R(-2) } & 0.010980 & 0.016532 & -0.019627 & 0.007113 & 0.004990 \\
\cline { 2 - 6 } & $(0.00969)$ & $0.01124)$ & $(0.00919)$ & $0.01194)$ & $(0.01349)$ \\
\cline { 2 - 6 } & {$[1.13352]$} & {$[1.47023]$} & {$[-2.13649]$} & {$[0.59589]$} & {$[0.36976]$} \\
\hline
\end{tabular}

Source: author calculations 
Overall, we find that all coefficients are statistically significant at the $5 \%$ level. For the oil price chains at the lag of 1 and 2, there is a positive impact (in other words, a positive effect) on the stock indexes in Japan and China. For India and Hong Kong markets, world oil prices fluctuated in the opposite direction with a 1-step lag. Particularly in the case of a 2-step lag return at oil prices has a positive effect on stock return in the Indian and Chinese markets. We look at the Korean stock market to see the negative impact on the return of world oil prices

\subsection{The Results of Estimating the Relationship of the Return Variability of Oil Prices Against Asian Stock Markets through the BEKK_GARCH Model}

Using the BEKK_GARCH model in this study, this article has given us a clearer picture of the volatility on the exchange of the world oil compared to the Asian stock. It is worth noting the variance and conditional covariance of diagonal representations in the BEKK model. The estimated results from the model presented in Table 6. With high statistical significance, most probability ratios are less than $1 \%$ in the results of the conditional variance of the estimated coefficients from the ARCH and GARCH models. Therefore, using the GARCH_BEKK model can capture the variability in oil price return and stock indexes between markets.

Table 6: The volatility relationship in oil prices return and Asian stock market return

\begin{tabular}{|c|c|c|c|c|c|}
\hline & $\begin{array}{c}\text { BSE_R \& } \\
\text { OIL_R }\end{array}$ & $\begin{array}{c}\text { HSI_R \& } \\
\text { OIL_R }\end{array}$ & $\begin{array}{c}\text { KS11_R \& } \\
\text { OIL_R }\end{array}$ & $\begin{array}{c}\text { N225_R \& } \\
\text { OIL_R }\end{array}$ & $\begin{array}{c}\text { SSCE_R \& } \\
\text { OIL_R }\end{array}$ \\
\hline ARCH test & $355.6019 *$ & $406.4698 *$ & $522.8529 *$ & $370.9935 *$ & $460.4461 *$ \\
\hline $\mathrm{m}_{11}$ & $6.73 \mathrm{E}-07 *$ & $6.10 \mathrm{E}-07 *$ & $4.78 \mathrm{E}-07 *$ & $1.50 \mathrm{E}-06 *$ & $1.85 \mathrm{E}-07 *$ \\
\hline $\mathrm{m}_{12}$ & $13 \mathrm{E}-08$ & $.49 \mathrm{E}-09$ & $2.13 \mathrm{E}-08$ & $4.65 \mathrm{E}-08$ & $-1.10 \mathrm{E}-08$ \\
\hline $\mathrm{m}_{22}$ & $6.19 \mathrm{E}-07 *$ & $6.07 \mathrm{E}-07 *$ & $5.51 \mathrm{E}-07 *$ & $5.07 \mathrm{E}-07 *$ & $6.62 \mathrm{E}-07^{*}$ \\
\hline$a_{1}$ & $0.266672 *$ & $0.223252 *$ & $0.262787 *$ & $0.330955 *$ & $0.223833^{*}$ \\
\hline & $0.218299 *$ & $0.220952 *$ & $0.213802 *$ & $0.213152 *$ & $0.226051^{*}$ \\
\hline$b_{11}$ & $0.945057 *$ & $0.961842 *$ & $0.948564 *$ & $0.916507 *$ & $0.973162 *$ \\
\hline$b_{22}$ & $0.972674 *$ & $0.972158 *$ & $0.974179 *$ & $0.974693 *$ & 0.970787 \\
\hline
\end{tabular}

Source: author calculations (* means P-value less than $1 \%$ )

The results show that the stock price index in all typical Asian markets has a strong dependence on its variation in the past, as demonstrated by the ARCH impacts. Besides, the magnitude of ARCH's estimation coefficients is quite small, which proves that the possibility of a significant change under the effects of improvements in profitability is unlikely. However, in the GARCH effect, it is shown that the latency of conditional return variation in future oil prices has a smaller impact than the return of the current variable. Furthermore, the coefficient value in GARCH indicates that the probability of a conditional variable will vary significantly in the future. The same is likely to be affected by world oil prices, but the analysis has revealed that the ARCH and GARCH impacts are quite similar between world oil prices and Asian stock markets. If you look at it more accurately, perhaps the price of oil has a more substantial impact on the Korean market (KS11_R), but the difference is tiny.

\subsection{Assess the Causal Relationship between Oil Price Return and the Asian Stock Market Return}

Results from the causal relationship between oil prices and Asian stock markets presented in Table 7 show the impact of oil prices on the stock market. In particular, only the Korean stock market is affected strongly with the probability rate at the permit table level of less than $5 \%$. This finding is a unidirectional effect, while the remaining stock markets do not suffer from Granger causality compared to world oil prices. This result prevented the hypothesis from being rejected, or in other words, oil price gains have an impact on the Korean stock market. This result does not surprise us, because the results from previous analyses also illustrate the relationship of the Korean stock market and oil prices in Tables 5 and 6 . This explains why, in 
the recent period, Korea became one of the countries with a tremendous US crude oil import in Asia. In the context of intense price competition in global financial markets and tensions in the U.S.-China trade disagreement, South Korea's crude oil imports have increased. At the same time, Korea is also the national price of refining oil for export, which is an excellent source of revenue for the country's economy.

Table 7: The Granger causality test of oil and stock price return

\begin{tabular}{|c|c|c|c|c|c|c|}
\hline \multicolumn{3}{|c|}{ Causal direction } & Obs & F-Statistic & Probability & Conclusion \\
\hline OIL_R & 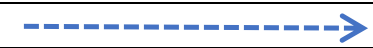 & BSE_R & 2470 & 0.80619 & 0.4467 & \multirow{10}{*}{$\begin{array}{l}\text { Oil price return } \\
\text { has causality on } \\
\text { the Korea stock } \\
\text { index return. }\end{array}$} \\
\hline BSE_R & 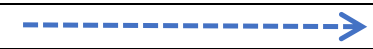 & \multicolumn{2}{|l|}{ OIL_R } & 1.09411 & 0.3350 & \\
\hline OIL_R & 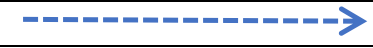 & HSI_R & 2472 & 1.75424 & 0.1733 & \\
\hline HSI_R & 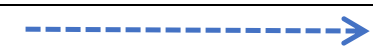 & \multicolumn{2}{|l|}{ OIL_R } & 0.49328 & 0.6107 & \\
\hline OIL_R & 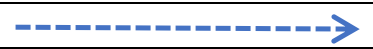 & \multirow{2}{*}{\multicolumn{2}{|c|}{$\frac{\text { KS11_R }}{\text { OIL_R }}$}} & 3.33041 & 0.0359 & \\
\hline KS11_R & 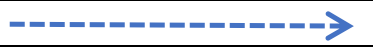 & & & 1.53843 & 0.2149 & \\
\hline OIL_R & 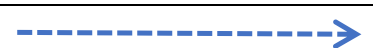 & \multirow{2}{*}{\multicolumn{2}{|c|}{$\frac{\text { N225_R }}{\text { OIL_R }}$}} & 0.33923 & 0.7123 & \\
\hline N225_R & 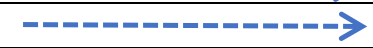 & & & 0.78157 & 0.4578 & \\
\hline OIL_R & 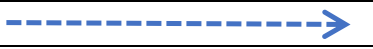 & \multirow{2}{*}{\multicolumn{2}{|c|}{ OIL_R }} & 0.12556 & 0.8820 & \\
\hline SSCE_R & 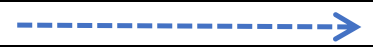 & & & 1.46246 & 0.2319 & \\
\hline
\end{tabular}

Source: author calculations

\section{Conclusion}

It is not surprising to see that in order to bridge the fiscal gap of revenue and expenditure, the Following the recent empirical studies, this study conducted to investigate the impact of oil prices on some of Asia's most representative stock markets, using the VAR, and BEKK_GARCH models. The author found that the model used for the study was consistent with the data. All data series have stationary at the first-degree difference of time series before conducting the analysis. Oil prices and Asian stock prices express the negative correlation, but the relationship between the stock markets is closely linked. The association in the return of world oil prices and return from Asian stock markets is not significant. When using the VAR model to look at the role of markets, it displays that the Korean market has similar results with an empirical analysis that has given from many previous research sources on the negative correlation between oil and stock indexes. Also, the Korean stock market has shown a causal relationship with oil prices through the Granger causality test. Concerning the profitability test of time data variables, it is clear that the interconnectedness and the effect of conditional variance in markets clearly expressed in a reasonably uniform degree between Asian stock and world oil. Here too, we state that the role of oil price volatility in the Korean stock market is higher than in the rest of the markets.

Oil plays a critical role in promoting economic growth, primarily through investment channels in the capital markets of Asian countries. A shock from oil prices can negatively affect the stable development of the economy, pushing it into recession and crisis, especially for countries whose economies are highly dependent on oil prices. Also, fluctuations in oil prices will affect the supply and demand of goods, create cost-inflation, destabilise the market, escalating costs, and directly affect people's lives. At the same time, they are widening the gap between rich and poor. The study also shows that, although oil price has a spillover effect on the stock market, this is a small negligible effect and has no severe impact on the Asian stock market in general. The stock market still operates quite independently before movements of oil prices as well as signals of the economy as research results have shown.

It will be difficult for a scenario of an oil price rebound. Therefore, we need to recognise the situation of low and long-lasting oil prices. The government should take the initiative in making 
budget revenue and expenditure plans on a national scale. The structure of state budget revenue should be designed following low-cost petroleum input. From there, we can seize opportunities based on the sharp decline in oil prices as in recent years. Each country will have a specific roadmap to limit and control the role of oil prices to the development of the stock price. Moreover, the government needs to be more proactive in developing other budget revenues from crude oil. In this way, the economies of countries will develop sustainably, contributing to limit the influence and dependence of world oil price shocks.

\section{Acknowledgements}

This research was supported by funding from the Faculty of Technology and Science of Danang Architecture University, Vietnam. I thank my supervisor so much for his helping - Dr. Jian Zihong, who always supports and gives me many good ideas. I also express my gratitude to our colleagues from the School of Economics, Huazhong University of Science and Technology, who provided insight and expertise that greatly assisted the research.

\section{References}

- Arouri, M. E. H., Lahiani, A., \& Nguyen, D. K. (2011). Return and volatility transmission between world oil prices and stock markets of the GCC countries. Economic Modelling, 28(4), 1815-1825. Crossref

- Basher, S. A., \& Sadorsky, P. (2006). Oil price risk and emerging stock markets. Global Finance Journal, 17(2), 224-251. Crossref

- Bollerslev, T. (1986). Bollerslev, Generalised Autoregressive Conditional Heteroskedasticity.pdf. Journal of Econometrics, 31, 307-327. Crossref

- Chittedi, K. R. (2012). Do Oil Prices Matters for Indian Stock Markets? An Empirical Analysis. Journal of Applied Economics and Business Research, 2(1), 2-10.

- Ciner, C. (2001). Energy Shocks and Financial Markets: Nonlinear Linkages. Studies in Nonlinear Dynamics \& Econometrics, 5(3), 11. Crossref

- Ciner, C. (2011). International Review of Financial Analysis Information transmission across currency futures markets: Evidence from frequency domain tests. International Review of Financial Analysis Information, 20, 134-136. Crossref

- Cunado, J., \& Perez de Gracia, F. (2014). Oil price shocks and stock market return: Evidence for some European countries. Energy Economics, 42, 365-377. Crossref

- El Hedi Arouri, M., Jouini, J., \& Nguyen, D. K. (2011). Volatility spillovers between oil prices and stock sector return: Implications for portfolio management. Journal of International Money and Finance, 30(7), 1387-1405. Crossref

- Engle, R. F. (1982). Autoregressive Conditional Heteroscedasticity with Estimates of the Variance of United Kingdom Inflation Stable. Econometrica, 50(4), 987-1007. Crossref

- Engle, R. F., \& Kroner, K. F. (1995). Multivariate simultaneous generalised arch. Econometric Theory, 11(1), 122-150. Crossref

- Fatima, T., \& Bashir, A. (2014). Oil Price and Stock Market Fluctuations: Emerging Markets (A Comparative Study of Pakistan and China). International Review of Management and Business Research, 3(4), 1958-1976.

- Fayyad, A., \& Daly, K. (2011). The impact of oil price shocks on stock market return: Comparing GCC countries with the UK and USA. Emerging Markets Review, 12(1), 61-78. Crossref

- Ferreira, P., Johson, É., Leão, D. A., Fernandes, M., \& Pereira, H. B. (2018). Detrended correlation coefficients between oil and stock markets: The effect of the 2008 crisis. Physica A, 1-28. Crossref

- Gokmenoglu, K. K., \& Fazlollahi, N. (2015). The Interactions among Gold, Oil, and Stock Market: Evidence from S\&P500. Procedia Economics and Finance, 25(January 2016), 478488. Crossref

- Granger, C. W. J., \& Lin, J. (1995). CAUSALITY IN THE LONG RUN. Econometric Theor, 11(2), 530-536. Crossref 
- Hamilton, J. D. (1983). Oil and the macroeconomy since world war II. Journal of Political Economy, 91(2), 228-248. Crossref

- Jammazi, R., Lahiani, A., \& Nguyen, D. K. (2015). A wavelet-based nonlinear ARDL model for assessing the exchange rate pass-through to crude oil prices. Journal of International Financial Markets, Institutions and Money, 34, 173-187. Crossref

- Jones, C. M., \& Kaul, G. (1996). Oil and the stock markets. Journal of Finance, 51(2), 463491. Crossref

- Khai, H. V., Sang, L. M., Thi, P., \& Nguyet, A. (2017). The impact of world crude oil prices on the Vietnamese Stock market. Southeast Asia Review of Economics and Business, I(1), 106-115.

- L. Kling, J. (1985). Oil price schocks and stock market behavior. The Journal of Porfolio Management, 12(1), 34-39. Crossref

- Li, Y., \& E.Giles, D. (2015). Modelling volatility spillover effects between developed stock markets and ASIAN emerging stock. International Journal of Finance \& Economics, 20, 155177. Crossref

- Mohanty, S., Nandha, M., \& Bota, G. (2010). Oil shocks and stock return: The case of the Central and Eastern European (CEE) oil and gas sectors. Emerging Markets Review, 11(4), 358-372. Crossref

- Nguyen, C. C., \& Bhatti, M. I. (2012). Copula model dependency between oil prices and stock markets: Evidence from China and Vietnam. Journal of International Financial Markets, Institutions and Money, 22(4), 758-773. Crossref

- Park, J., \& Ratti, R. A. (2008). Oil price shocks and stock markets in the U.S. and 13 European countries. Energy Economics, 30(5), 2587-2608. Crossref

- Sadorsky, P. (1999). Oil price shocks and stock market activity. Energy Economics, 21(5), 449-469. Crossref

- Sharma, A., Giri, S., Vardhan, H., Surange, S., Shetty, R., \& Shetty, V. (2018). Relationship between Crude Oil Prices and Stock Market: Evidence from India. International Journal of Energy Economics and Policy, 8(4), 331-337.

- Siddiqui, S., \& Gaur, A. (2017). Time-Varying Conditional Correlation in Crude Oil and BSE S \& P Sensex: An Application of Multivariate GARCH Models. Proceedings of International Conference on Strategies in Volatile and Uncertain Environment for Emerging Markets, 608616. Indian Institute of Technology Delhi, New Delhi: Indian Institute of Technology Delhi, New Delhi.

- Tursoy, T., \& Faisal, F. (2017). The impact of gold and crude oil prices on stock market in Turkey: Empirical evidences from ARDL bounds test and combined cointegration. ScienceDirect Resources Policy Journal, (25 October 2017), 0-1. Crossref

- Yahya, M., Hussin, M., Muhammad, F., Razak, A. A., Tha, G. P., Marwan, N., Idris, S. (2013). The Link between Gold Price, Oil Price and Islamic Stock Market: Experience from Malaysia. Journal of Studies in Social Sciences, 4(2), 161-182.

- Zankawah, M. M., \& Stewart, C. (2019). Measuring volatility spillover effects of crude oil prices on Ghana's exchange rate and stock market between 1991 and 2015. London. 